\title{
O PERCURSO DO CONTRATO DE LEGITIMAÇÃO PARA O DESENVOLVIMENTO SUSTENTÁVEL: ANÁLISE DOS TEMAS ATRELADOS NO RELATO INTEGRADO DO BNDES
}

\author{
Kelli Juliane Favato 1 \\ Marguit Neumann 2 \\ Simone Leticia Raimundini Sanches 3
}

- Artigo recebido em: 21/03/2019 -- Artigo aceito em: 06/02/2020 -.- Segunda versão aceita em: 06/03/2020

\section{RESUMO}

Os bancos de desenvolvimento atuam concedendo financiamento a projetos de longo prazo em vista ao desenvolvimento. O Banco Nacional de Desenvolvimento Econômico e Social (BNDES) que é o maior banco de desenvolvimento da América Latina e um dos maiores do mundo, adotou voluntariamente o Relato Integrado em 2013. Este estudo objetivou analisar quais os temas relacionados ao desenvolvimento sustentável que o BNDES tem trabalhado no Relato Integrado e realizar um levantamento biográfico com reflexões sobre o percurso das fases de mandatos políticos do banco entre as décadas de 1960 e os anos 2000. A sustentação teórica é com a ótica da Teoria da Legitimidade, acrescida da discussão sobre desenvolvimento sustentável com os fatores econômico, social e ambiental. Aplicou-se a técnica de análise de conteúdo nos relatos dos anos de 2013 a 2016. Conclui-se que o BNDES consegue atrelar capital econômico, social e ambiental, mas faltam indicadores para mensurá-los. Este estudo contribui ao inferir que o Relato Integrado pode ser uma forma comunicação do contrato de legitimação do banco com diversos stakeholders para o desenvolvimento sustentável, atrelando

\footnotetext{
1 Doutoranda em Ciências Contábeis pelo Programa de Pós-Graduação em Ciências Contábeis (PPGCONT) na Universidade Federal do Paraná (UFPR). Mestre em Ciências Contábeis pela Universidade Estadual de Maringá (UEM). Endereço: Avenida Prefeito Lothário Meissner, 632 - $1^{\circ}$ Andar - Sala 120, Jardim Botânico - Curitiba/PR, Brasil. E-mail: kelli.favato@gmail.com. https://orcid.org/0000-0001-8360-8318
}

2 Doutora em Sciences Economiques pela Université Pierre Mendès France. Professora na Universidade Estadual de Maringá (UEM), Programa de Pós-Graduação em Ciências Contábeis (PCO-UEM). Endereço: Av. Colombo, 5790 - Campus Universitário - Bloco C23, sala 227 - Maringá/PR, Brasil. E-mail: marguitn26@gmail.com.

https://orcid.org/0000-0003-1246-3769

3 Doutora em Administração pela Universidade Federal do Rio Grande do Sul. Professora na Universidade Estadual de Maringá (UEM), Programa de Pós-Graduação em Ciências Contábeis (PCO-UEM), Universidade Estadual de Maringá (UEM). Endereço: Av. Colombo, 5790 - Campus Universitário - Bloco C23, sala 227 - Maringá/PR, Brasil. E-mail: slraimundini@vem.br.

https://orcid.org/0000-0002-7363-2573

Editora responsável pela aprovação do artigo: Dr ${ }^{a}$. Bruna Camargos Avelino Editora responsável pela edição do artigo: $\mathrm{Dr}^{a}$. Bruna Camargos Avelino 
O Percurso do Contrato de Legitimação para o Desenvolvimento Sustentável: Análise dos Temas Atrelados no Relato Integrado do BNDES

a missão do banco de desenvolvimento a longo prazo ainda que a sua gestão esteja relaciona aos mandatos públicos de curto prazo.

Palavras-chave: Desenvolvimento sustentável; Relato integrado; BNDES.

\title{
THE PATH OF THE LEGITIMATION CONTRACT FOR SUSTAINABLE DEVELOPMENT: AN ANALYSIS OF THE THEMES LINKED IN INTEGRATED REPORT OF THE BNDES
}

\begin{abstract}
Development Banks Act by granting financing to long-term projects in view of development. The National Bank for Economic and Social Development (BNDES) is the largest development bank in Latin America and one of the largest in the world, voluntarily adopted the integrated report in 2013. This study aimed to analyze which issues related to the sustainable development that BNDES has worked on in the integrated report and to conduct a biographical survey with reflections on the trajectory of the phases of political mandates of the bank between the decades 60 and the 2000 years. The theoretical support is based on the Theory of Legitimacy, plus the discussion on sustainable development with economic, social and environmental factors. The content analysis technique was applied in the reports from 2013 to 2016 years. It is concluded that the BNDES manages to engage economic, social and environmental capital, but the lack of indicators to measure them. This study contributes to the inference that the integrated report can be a form of communication of the bank's legitimation contract with several stakeholders for sustainable development, linking the longterm Development Bank's mission even though its Management is related to short-term public mandates.
\end{abstract}

Keywords: Sustainable development; Integrated Report; BNDES.

\section{INTRODUÇÃO}

Embora países desenvolvidos tenham despertado para questões de recuperação ambiental, o mundo como um todo, percorre um caminho não sustentável frente a um sistema de produção e consumo de curto prazo. De modo, tanto a Fabula para o Amanhã de Carson (1969), proferindo a Primavera Silenciosa que procedeu da ineficiência do uso de recursos naturais, quanto o papel do desenvolvimento das relações econômicas e políticas para a expansão da liberdade social posta por Sen (2000), demonstram serem preocupações atuais.

A nível de Estado, contrapondo o mercado financeiro com uma visão restrita de crescimento e liquidez, os bancos de desenvolvimento atuam concedendo financiamento a projetos de longo prazo em vista ao desenvolvimento de determinadas áreas. A atuação destas instituições poderá equilibrar o aspecto de crescimento para o desenvolvimento (Aronovich \& Fernandes, 2006; Lazzarini et al, 2015; Sen, 2000). No Brasil, esse papel compete 
ao Banco Nacional de Desenvolvimento Econômico e Social (BNDES), que é o maior banco de desenvolvimento da América Latina e um dos maiores do mundo, representando mais de $20 \%$ do total de crédito ao setor privado e a maior parte do crédito de longo prazo (Lazzarini et al., 2015; Souza et al., 2015). Fornecendo $73 \%$ do financiamento de longo prazo (empréstimos em três anos) no Brasil (Doctor, 2015).

Para Hanley et al. (2016) o BNDES tem papel relevante, porém, algumas vezes, controverso no desenvolvimento econômico, tanto como provedor de financiamento a longo prazo, quanto como impulsionador político de curto prazo. Isto porque a história do BNDES coincide com os diferentes estágios de desenvolvimento políticos no Brasil, dos quais a instituição promovia financiamento de temas (áreas) a serem desenvolvidas, alinhadas com as propostas governamentais. Disto, surgem anseios para compreender o que o BNDES representa nacionalmente e como tem trabalhado o desenvolvimento sustentável, pois a sua missão consiste em viabilizar soluções financeiras que adicionem investimentos para o desenvolvimento sustentável no contexto nacional. Para tanto, pergunta-se: Quais os temas relacionados ao desenvolvimento sustentável o BNDES tem trabalhado?

Para responder essa questão, objetiva-se analisar, com a ótica da teoria da legitimidade, quais os temas relacionados ao desenvolvimento sustentável que $O$ BNDES tem trabalhado no relato integrado. Compreende-se que a instituição adotar o com a perspectiva desenvolvimento sustentável a longo prazo pode ser visto como alternativa para atingir coesão social, conectar-se ao progresso mundial e legitimar na sociedade como desenvolvedor sustentável. No Brasil a Lei 13.303/2016 (para empresas estatais e mistas) determina a obrigatoriedade da divulgação anual de Relato Integrado ou de Sustentabilidade, no entanto O BNDES aderiu a proposta do IIRC em 2013, quando ainda era um aspecto voluntário. A normativa mais recente é do Tribunal de Contas da União (TCU 170 de 19/09/2018)i com a decisão de adotar - para a prestação de contas da Administração Pública Federal.

Para delimitação da proposta, utilizou-se a análise de conteúdo dos Relatos Integrado entre os anos de 2013 e 2016, período este de publicação pelo BNDES. Com objetivo secundário para a resposta de pesquisa, foi realizado um levantamento biográfico do percurso do BNDES entre as décadas de 1960 e os anos 2000.

A justifica para este estudo está em considerar que os elementos divulgados no Relato Integrado do BNDES apresentam uma janela do que seriam os atributos setoriais e regionais para o desenvolvimento sustentável do Brasil e efetiva transformação (desenvolvimento) da sociedade brasileira. Em outras palavras, os elementos divulgados possibilitam evidenciar se o caminho desse contrato social, de ser sustentável, está sendo percorrido e em quais projetos estão sendo incentivados.

As diretrizes para as operações realizadas ao longo desse tempo é uma questão importante para a academia (Souza et al., 2015), mas, como posto por Lazzarini et al. (2015), apesar da importância, não se tem uma compreensão clara do que o banco de desenvolvimento faz na prática. Embora haja uma vasta literatura examinando-o, grande parte é representada por pesquisas incentivadas ou financiada pelo próprio BNDES, levando a uma generosa 
O Percurso do Contrato de Legitimação para o Desenvolvimento Sustentável: Análise dos Temas Atrelados no Relato Integrado do BNDES

interpretação (Hanley, Pires, Marcondes, Faria, \& Sakurai, 2016, p.827 ). E na área de ciências sociais aplicadas a parcela de publicação é ainda menor.

As principais contribuições dessa pesquisa consistem em relacionar pressupostos da teoria da legitimidade como um processo de retorno as pressões políticas e sociais para com o BNDES. Em termos práticos contribui, para evidenciar que $O$ BNDES incorporou $O$ paradigma do desenvolvimento sustentável, apesar de não ter conseguido medir ou mensurar.

\section{REVISÃO DE LITERATURA}

\subsection{Desenvolvimento Sustentável e Teoria da Legitimidade Organizacional}

Para planejar estratégias a longo prazo (por exemplo, quanto à competividade da taxa de inovação, a sustentabilidade da demanda por uma linha de produtos ou manter o capital intelectual de uma empresa) o conceito de capital econômico precisará absorver cada vez mais uma gama de conceitos envolvendo perspectivas naturais e sociais (Elkington, 2012). Para Elkington (2012), é necessário entender quais os tipos de atividades financeiras, industriais e empreendedoras o mundo sustentável irá necessitar.

Entende-se que a Responsabilidade Socioambiental Corporativa (RSC) não é unilateral da empresa ou tática oportunista para limpar a sua imagem (Abramovay, 2012), mas sim uma resposta a pressões de grupos com diferentes olhares e poderes na instituição que notam a ampliação dos riscos empresariais e voltam-se para que as entidades revejam a base na qual realizam seus negócios (Abramovay, 2012; Freeman \& Evan, 1990).

Diante dos fatores de pressão, as organizações tem adotado relatórios de impactos socioambientais, o que para a teoria da legitimidade, que é uma teoria sócio-política (Gray et al., 1995), é uma estratégia frente a necessidade de evitar qualquer ameaça a legitimidade da organização e seu ambiente, provida da relação entre os mesmos (Cho et al., 2012; Deegan, 2002; Roberts, 1992). A teoria da legitimidade sustenta o argumento que se uma organização não justificar a sua continuidade perante a sociedade, os seus membros se encarregarão de revogar o contrato social (Deegan, 2002; Richardson, 1987; Suchman, 1995).

Assim, a legitimação é o processo em que a entidade justifica o seu direito de existir (Fank \& Beuren, 2010; Suchman, 1995), logo, a organização será considerada legítima se atender aos objetivos socialmente aceitos pela sociedade, demonstrando/evidenciando que opera dentro dos limites da mesma (Chen \& Roberts, 2010; Cosenza, Mamede, \& Laurencel, 2010; Deegan, 2002). O enfoque da teoria da legitimidade é voltado para o tipo de informação divulgada e a mensagem que se espera transmitir com ela, considerando que existe um contrato entre sociedade e empresa. Dessa forma que a sociedade requer produtos e serviços da empresa e está recebe a aprovação desta, ou seja, na medida que os valores da organização se alinham aos da sociedade, alcança-se a legitimidade (Cosenza et al., 2010; Fank \& Beuren, 2010; Suchman, 1995). Supõe-se que as empresas devam tomar medidas que assegurem que as atividades sejam aceitas pela comunidade. 
Cho et al. (2012) e Hopwood (2009) inferem quanto a necessidade de mudança e melhoria no papel que a gestão pode desempenhar na esfera de sustentabilidade, uma vez que enquanto a legitimidade econômica das corporações é monitorada por meio do mercado, a legitimidade social é monitorada por meio do processo de políticas públicas. Preston e Post (1981) ditam que legitimidade social da empresa depende da sua capacidade de atender às expectativas de desempenho de seus stakeholders. Embora as primeiras iniciativas na área de relatórios ambientais corporativos tenham avançado em pequena escala, há sinais de pressões dos diversos stakeholders por uma mudança concreta e transparente (Hopwood, 2009).

Nesse sentido para Abramovay (2010) o crescimento industrial brasileiro poderá ficar cada vez mais defasado quanto aos avanços tecnológicos mundiais, exemplificando com os carros elétricos ou o emprego de bots em larga escala. O que para o autor, (Abramovay, 2010), é uma consequência do falho papel nas políticas públicas ao não alinhar com atores sociais quais serão os comportamentos necessários a longo prazo para uma estratégia sustentável. Preston e Post (1981) mencionam ser necessário analisar e monitorar os desenvolvimentos para extrair propostas relevantes entre corporações e desenvolvimento sustentável.

\subsection{Relato Integrado: Proposta de Integração dos Elementos Financeiros e Não Financeiros}

O Relato Integrado (RI) é um recente desenvolvimento após 30 anos ou mais de tentativas em ampliar a prestação de contas para incluir maior impacto social e ambiental no negócio, visando comunicar de forma eficaz aos stakeholders como as entidades criam valor a longo prazo (Stubbs \& Higgins, 2015). A perspectiva é que a longo prazo, seja um padrão de relatos que proporcione as organizações reduzirem as numerosas comunicações para integrar seus números de forma conectiva e assertiva (IIRC, 2013), direcionando para desempenho economicamente viável, socialmente justo e ambientalmente correto (Elkington, 2012). A mudança do financeiro para uma visão múltipla, a longo prazo é consistente com pesquisas que desafiaram os valores do tradicional relatório anual (Gray, 2010; Thomson, 2015).

É válido o objetivo do International Integrated Reporting Council [IIRC] de criar o Rl, em 2010, como uma estrutura de relatórios corporativos globalmente aceitos que integre informações financeiras, ambientais, sociais e de governança em um formato claro, conciso, consistente e comparável (Thomson, 2015). Para Adams (2015) a proposta de incentivar os tradicionais gestores a pensar a longo prazo é ousada, porém importante visto que em torno do Relato Integrado existe a expectativa de que o mesmo tenha potencial de mudar o pensamento corporativo e alinhar as noções de maximização do lucro com o bem-estar socioambiental.

Uma das particularidades RI é o prestígio e soberania do corpo de diretores do seu conselho (IIRC), representado pelo The International Accounting Standards Board (IASB), The Financial Accounting Standards Board (FASB), The Internation Federation of Accountant (IFAC) e The International Organization of Securities (IOSCO), os CEOs das Big Four, os chefes dos principais órgãos dos profissionais de contabilidade britânicos e os CFOs das principais multinacionais, 
O Percurso do Contrato de Legitimação para o Desenvolvimento Sustentável: Análise dos Temas Atrelados no Relato Integrado do BNDES

entre outros (Flower, 2015, p. 2). Percebe-se relevância do âmbito acadêmico em acompanhar o seu desenvolvimento (Burke \& Clark, 2016; Flower, 2015; Perego et al., 2016; Thomson, 2015), adotando uma postura ativa e cautelosa em relação as movimentações do mercado quanto ao desenvolvimento sustentável (Perego et al., 2016).

O Rl é baseado na suposição de usuários empoderados para monitorar, recompensar e punir organizações com práticas não aceitáveis (Thomson, 2015). Nesta proposta, as estratégias de negócio devem ser direcionadas ao interesse de um grupo mais amplo de agentes (Magill, Quinzii \& Rochet, 2015), o que provoca uma preocupação nas entidades em adequar as suas atividades para um plano sustentável e comunicar aos stakeholders as estratégias de iniciativas socioambientais de maneira assertiva e conectiva, em busca da legitimidade organizacional.

\section{PROCEDIMENTOS METODOLÓGICOS}

Esta pesquisa apresenta dois levantamentos, um biográfico e outro documental. Quanto a esse, primeiramente foi realizada uma busca na plataforma da Coordenação de Aperfeiçoamento de Pessoal de Nível Superior (Capes), Web of Science e Scielo, restringindo a título igual a BNDES ou BNDE, dentro da área de ciências sociais aplicadas, resultando em apenas 17 pesquisas que não são financiadas pelo banco, conforme Tabela 1.

\section{Tabela 1}

Estudos voltados ao contexto do BNDES

\begin{tabular}{l|l}
\hline \multicolumn{1}{c}{ TEMA } & \multicolumn{1}{c}{ PESQUISAS } \\
\hline $\begin{array}{l}\text { Papel do banco } \\
\text { para o } \\
\text { desenvolvimento } \\
\text { local }\end{array}$ & $\begin{array}{l}\text { Lazzarini, Musacchio, Bandeira-de-mello, \& Marcon, 2015; } \\
\text { Rezende, 2015; Simonassi, Arraes, \& Silva, 2017; Torres \& } \\
\text { Nogueira, 2012. }\end{array}$ \\
$\begin{array}{l}\text { Influência política } \\
\text { Schapiro, 2017; Kraychete, 2016; Ferraz \& Coutinho, 2017; } \\
\text { Hochstetler, 2014; Sobreira \& Martins, 2011. } \\
\text { Latres, Lemos, Falcón, \& Magalhães, 2014; Pezzin, 2015; } \\
\text { Schlickmann, 2016; Silva \& Pereira, 2017; Quaglio \& Paiva, 2017; }\end{array}$ \\
$\begin{array}{l}\text { Garzon, 2015. } \\
\text { Bibliométricos }\end{array}$ \\
\hline
\end{tabular}

Nota. Fonte: busca realizada na plataforma da Coordenação de Aperfeiçoamento de Pessoal de Nível Superior (Capes), Web of Science e Scielo.

Percebe-se o ínfimo direcionamento de pesquisas investigando o BNDES, que não são incentivadas pelo próprio órgão e que há poucas pesquisas indexadas nas bases de dados. Além disso ressalta-se que nenhuma pesquisa está voltada para a área contábil ou para analisar os relatórios de sustentabilidade publicados pelo BNDES e a de legitimação da sua atuação perante a sociedade. Diante desse resultado bibliográfico, propôs-se uma seção biográfica para relatar como foi o percurso do BNDES durante as 6 décadas de existência.

Após incorporar o percurso do BNDES, esta pesquisa também é documental, isto é, trabalha com o Relato Integrado do BNDES entre os anos 2013 a 2016. A delimitação temporal representa todo o período de divulgação 
do Relato Integrado pela instituição. Esses documentos foram analisados pela técnica de análise de conteúdo, proposta por Bardin (2016) (Figura 1).

\begin{tabular}{|c|c|c|}
\hline I Pré-análise & $\begin{array}{c}\text { II Exploração do } \\
\text { Material }\end{array}$ & $\begin{array}{c}\text { III Tratamento de Resultados } \\
\text { e Interpretação }\end{array}$ \\
\hline $\begin{array}{l}\text { 1. Exploração do material. } \\
\text { 2. Seleção de } 5 \text { RI com } \\
\text { diretrizes do IIRC. } \\
\text { 3. Formulação da análise: } \\
\text { estratificar dados para } \\
\text { responder ao objetivo de } \\
\text { pesquisa. } \\
\text { 4. Formulação de índices: } \\
\text { Desenvolvimento Sustentável. } \\
\text { 5. Preparação do material. }\end{array}$ & $\begin{array}{l}\text { 1. Realizar a } \\
\text { administração } \\
\text { sistêmica dos itens } \\
\text { codificados e } \\
\text { categorizados. }\end{array}$ & $\begin{array}{l}\text { 1. Definir que a melısagem é o } \\
\text { próprio Rl e o emissor o BNDES. } \\
\text { 2. Utilizar o software Atlas*ti } \\
\text { versão } 8.2 \text { para analisar as } \\
\text { codificações realizadas. }\end{array}$ \\
\hline
\end{tabular}

Figura 1. Ełapas da análise de conteúdo

Fonte: elaborada com base em Bardin (2016).

Na fase 4 (codificação) da I Pré-análise (Figura 1), o índice foi elaborado considerando o problema de pesquisa em responder quais os temas relacionados ao desenvolvimento sustentável o BNDES tem trabalhado no RI e, relacionando isso com a literatura apresentada.

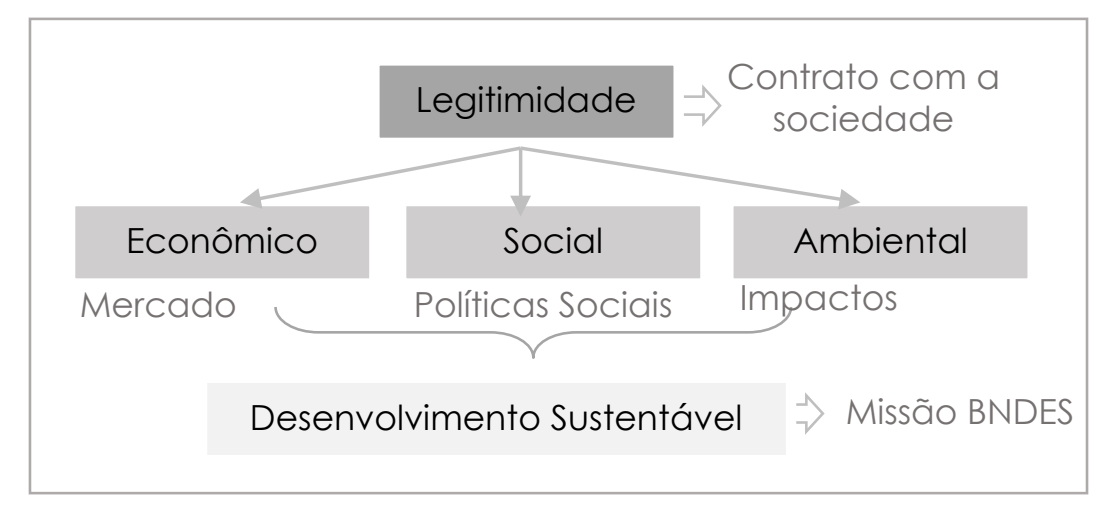

Figura 2. Formulação do índice Desenvolvimento Sustentável.

Fonte: Elaborado com base em Preston e Post (1981); Hopwood (2009); Cho et al. (2012); Elkington (2012).

A literatura (Cho et al., 2012; Hopwood, 2009; Elkington, 2012; Richardson, 1987; Suchman, 1995) foi utilizada para delimitar o desenvolvimento sustentável como forma de legitimidade de uma organização perante seu contrato com a sociedade. Nota-se que os mesmos correspondem a missão do BNDES.

Após a formulação do índice, foi possível estabelecer 2 unidades de contexto (Tabela 2). O processo de identificação das unidades de contexto levou em consideração que a unidade de registro é o parágrafo. A partir de então, foi analisado na unidade de registro (dentro dos parágrafos) a codificação (índice desenvolvimento sustentável) e identificou-se que a codificação estava relacionada as unidades de contexto voltadas para falas 
O Percurso do Contrato de Legitimação para o Desenvolvimento Sustentável: Análise dos Temas Atrelados no Relato Integrado do BNDES

institucionais ou apresentando os projetos que o banco considera na dimensão de desenvolvimento sustentável. Quanto a categorização, optou-se pelo sentido sintético da palavra, seguindo a técnica de Bardin (2016).

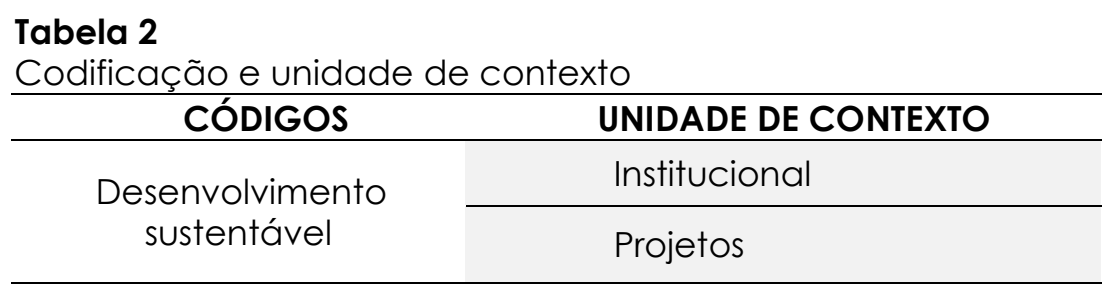

Ressalta-se que na fase 2 da III etapa, o software Atlas*ti versão 8.2 foi utilizado como ferramenta complementar para encontrar no texto quais são os temas que envolvem desenvolvimento sustentável apresentado pelo BNDES. Para isso, foi utilizada a ferramenta autocoding com os termos desenvolvimento sustentável, além de leitura flutuante visando ter o máximo de percepção do conteúdo. Após, foram codificadas as palavras de acordo com a categorização proposta nesse modelo, utilizou-se a ferramenta teia de relação para visualizar quais temáticas o banco envolve para o conceito de desenvolvimento sustentável.

\section{APRESENTAÇÃO DOS RESULTADOS}

\subsection{Reflexões sobre o Percurso do BNDES}

No Brasil, país que historicamente tem poucos investimentos e consideráveis limitações sociais e de infraestrutura, a missão de investir para desenvolver é de suma importância (BNDES, 2017). O BNDES é considerado um dos maiores e mais rentáveis bancos de desenvolvimento do mundo (Lazzarini et al., 2015; Souza et al., 2015) e passou por diversas fases ao longo do tempo, com indícios de que o principal foco não estava concentrado em desenvolver, mas sim, fortalecer um setor de interesse estratégico (Souza et al., 2015). Logo, requer atenção especial quanto à avaliação dos seus impactos no investimento nacional.

Instituído em 1952, até então como Banco Nacional de Desenvolvimento (BNDE), a sua gestão era concentrada pelas políticas de Estado voltando-se para expansão de setores estratégicos, principalmente, para renovação do sistema ferroviário e a construção de novas usinas hidrelétricas (Bndes, 2017; Lazzarini et al., 2015). A maioria dos grandes projetos financiados pelo BNDE foi destinada para grandes empresas estatais. No final dos anos 1950, o foco do banco transitou para dar apoio ao desenvolvimento da indústria de aço ainda incipiente no país, afim de diminuir a dependência dos mercados externos e incentivar o mercado doméstico. O BNDE atuou como uma holding de várias empresas siderúrgicas e acabou financiando de $70 \%$ a $80 \%$ dos seus investimentos (Doctor, 2015; Lazzarini et al., 2015).

Após a década de 1960, durante o governo militar (1964-1985), O BNDE mudou o foco de empréstimos voltados a projetos públicos, para então, financiar grupos privados que desenvolviam novas indústrias ou novas tecnologias que ajudariam a substituir importações e fomentar as indústrias 
nacionais (Doctor, 2015). A estratégia consistiu em fornecer capital para fabricantes de máquinas e equipamentos e fomentar capital de crescimento para o setor privado, especialmente, nas indústrias de produtos químicos e bens de consumo, para tanto o BNDE criou três subsidiárias que lhe permitiram financiar a venda de máquinas e equipamentos (Bachiller, 2016; Colombo \& Andrade, 2016; Lazzarini et al., 2015).

Com o choque do petróleo de 1979 e a crise da dívida de 1982, o BNDE tornou-se um hospital para empresas em dificuldades, financiando a reestruturação de empresas estatais e socorrendo empresas privadas por meio de investimentos acionários ou até mesmo empréstimos. Em 1982, o banco acrescentou o objetivo do desenvolvimento social à sua missão - mudando sua sigla de BNDE para BNDES ( $S$, social) - e fundiu todos os seus programas de investimento em ações em um novo braço acionário chamado BNDES Participações (BNDESPAR). Na década de 1990, reinventou sua missão durante a onda de privatizações (principalmente no mandato do presidente Fernando Henrique Cardoso 1995-2002) (Bachiller, 2016; Colombo \& Andrade, 2016; Lazzarini et al., 2015).

Na gestão de 2003-2010 (mandato o presidente Luiz Inácio Lula da Silva), o BNDES esteve envolvido em operações de grande escala estruturando fusões e aquisições para construir grandes grupos corporativos. Em torno de $60 \%$ dos empréstimos tem como alvo grandes empresas com faturamento anual superior a US $\$ 130$ milhões. Para Hochstetler (2014) os desembolsos anuais do BNDES mais do que quadruplicaram, chegando a ser três vezes o tamanho do empréstimo anual do Banco Mundial em 2010, foi neste período que iniciou-se a política de internacionalização.

Indaga-se se o papel mais recente do BNDES na economia brasileira é tão claro quanto no pós-guerra, que visava desenvolver bases para 0 desenvolvimento do país, uma vez que nessa gestão os esforços foram estabelecidos para fortalecimento de alguns grandes grupos empresariais que poderiam emprestar fundos de outras instituições com taxas de juros praticadas as outras empresas (Lazzarini et al., 2015).

Algumas estratégias do BNDES podem acarretar distorções nos mercados de crédito, por exemplo, após 2002 a proporção de financiamento do BNDES proveniente diretamente do Tesouro Nacional aumentou significativamente e esses recursos foram financiados com novas dívidas públicas, para as quais o governo teve que pagar taxas de mercado acima da taxa subsidiada de Taxa de Juros de Longo Prazo (TJLP) cobrada pelo BNDES em seus empréstimos. Assim, as transferências do Tesouro estavam aumentando a dívida pública (Doctor, 2015; Giambiagi, Pinheiro, \& Giambiagi, 2011 ; Lazzarini et al., 2015).

Outra consequência das estratégias do BNDES é o desequilíbrio do desenvolvimento regional, este que deveria ser sua missão. Para Pezzin (2015), desde os anos 2000 há um agravante devido as diversas fusões e aquisições que ocorreram entre as concessionárias, acarretando um processo de oligopolização e internacionalização do controle de ativos estratégicos da infraestrutura de transportes nacional, privatizações e transferências de rendimentos. São algumas consequências dessa política que deveria aplicar recursos para minimizar a problemática da questão regional brasileira. 
Para Doctor (2015) o BNDES exerceu na década de 1960 três papéis principais e dois complementares. Suas funções principais incluem: credor (direta e indiretamente via atividades de repasse de bancos comerciais), investidor de capital (acionista e capitalista de risco) e gerente de privatização (não mais um papel central como na década de 1990). Seus papéis complementares, relativamente novos, estão relacionados ao apoio à estabilidade macroeconômica (via empréstimos anticíclicos) e ao financiamento da internacionalização das empresas brasileiras (Doctor, 2015). Papéis estes que estão alinhados com o que se espera de um banco nacional de desenvolvimento.

Em um panorama geral do percurso do BNDES, nota-se que o mesmo permanece consciente de que deve responder ao mandato do governo. Para Doctor (2015) o percurso do BNDES fornece alguns fundamentos para acreditar que o mesmo está em posição (estrutura e técnica) de gerenciar de maneira responsável e transparente suas ações futuras para continuar fornecendo os bens públicos essenciais em fundos de investimento de longo prazo e conhecimento técnico para promover o desenvolvimento do Brasil. No entanto, seria prepotente afirmar um resultado garantido, isso porque a aplicação e administração de recursos, logicamente, dependerá de como os futuros governos utilizarão os recursos do banco para o desenvolvimento do País, bem como, a forma com que os governantes traçam estratégias para desenvolver os setores que carecem de investimentos, e administração de regiões que necessitam avançar economicamente de maneira a se desenvolver sustentavelmente. Em vista a compreender como o BNDES tem tratado a questão sustentável atualmente, foi desenvolvida a próxima seção que aborda os temas atrelados a desenvolvimento sustentável divulgados pela instituição no Relato Integrado.

\subsection{Analise dos Relatos Integrado do BNDES}

Foi possível identificar 23 temas relacionados ao desenvolvimento sustentável nos Relatos Integrado analisados. É possível identificar que os referidos temas representam dois grupos de contexto, (i) institucional e (ii) projetos. Na Tabela 3 estão apresentados os temas relacionados a divulgação de desenvolvimento sustentável do BNDES, segregados na unidade de contexto (i) institucional. 
Tabela 3

Relações encontradas ao tema institucional

\begin{tabular}{ll}
\hline \multicolumn{1}{c}{ Contexto Apresentado } \\
\hline & Considera a relevância das \\
& questões socioambientais para \\
1- Aperfeiçoamento & a atuação e para o \\
de Contratos & desenvolvimento sustentável do \\
& país, promove um \\
& aperfeiçoamento das cláusulas \\
contratuais adotadas.
\end{tabular}

2 - Busca por

Excelência

\section{3 - Concessão de Financiamento}

\section{4 - Criar Valor}

\section{5 - Desafios}

6 - Diretrizes para Apoio Financeiro

\section{7 - Estratégico}

8 - Missão

9 - Monitoramento de Projetos
Ter funcionários concursados.

Participação em fóruns internacionais

Avalia de acordo com parâmetros previamente estabelecidos se 0 pedido contribui para o desenvolvimento sustentável. Sistema de Monitoramento e Avaliação (M\&A) (Relatório de Efetividade 2007-2014) formulação de políticas públicas; execução de estratégias de desenvolvimento sustentável; inclusão social e produtiva. Os desafios regionais, socioambientais e da inovação para o desenvolvimento sustentável.

O Departamento de Prioridades e Enquadramento para avaliar as dimensões do projeto.

Desenvolvimento sustentável e competitivo, sustentabilidade financeira, processos internos e aprendizado; competências.

Promover o desenvolvimento sustentável e competitivo da economia brasileira, com geração de emprego e redução das desigualdades sociais e regionais

Medir o grau de contribuição do Banco para o desenvolvimento sustentável, alinhado com as políticas de desenvolvimento do Governo Federal.

\section{Análises dos Autores}

O Banco não detalha lou não exemplifica) quais são as alterações propostas e qual dimensão isso pode impactar.

O concurso é uma consequência por ser banco público, não citou quais os incentivos concedidos aos servidores para atuarem e promoverem o desenvolvimento sustentável. Não detalha ações promovidas nos fóruns.

Não divulga quais são os parâmetros de desenvolvimento sustentável que 0 banco considera.

O sistema visa criar indicadores que monitoram a atividade do BNDES (não foram apresentados no relatório). O banco considera que esses três pontos são as entregas para a sociedade, mas não os detalha nesse tema do RI.

O banco ressalta que prioriza as demandas de desenvolvimento regional.

O setor avalia se contribui para o desenvolvimento sustentável, se a empresa apresenta as condições necessárias para assumir o financiamento, se há risco ambiental no projeto.

A estratégia do banco consiste nos 4 itens.

Vale frisar a missão de reduzir desigualdades sociais e regionais.

Divulga que 0 monitoramento consiste na aplicação de técnicas quantitativas e qualitativas para explicitar os objetivos das operações realizadas e medir seu alcance e que mais detalhes poderão ser encontrados na Revista BNDES. 
O Percurso do Contrato de Legitimação para o Desenvolvimento Sustentável: Análise dos Temas Atrelados no Relato Integrado do BNDES

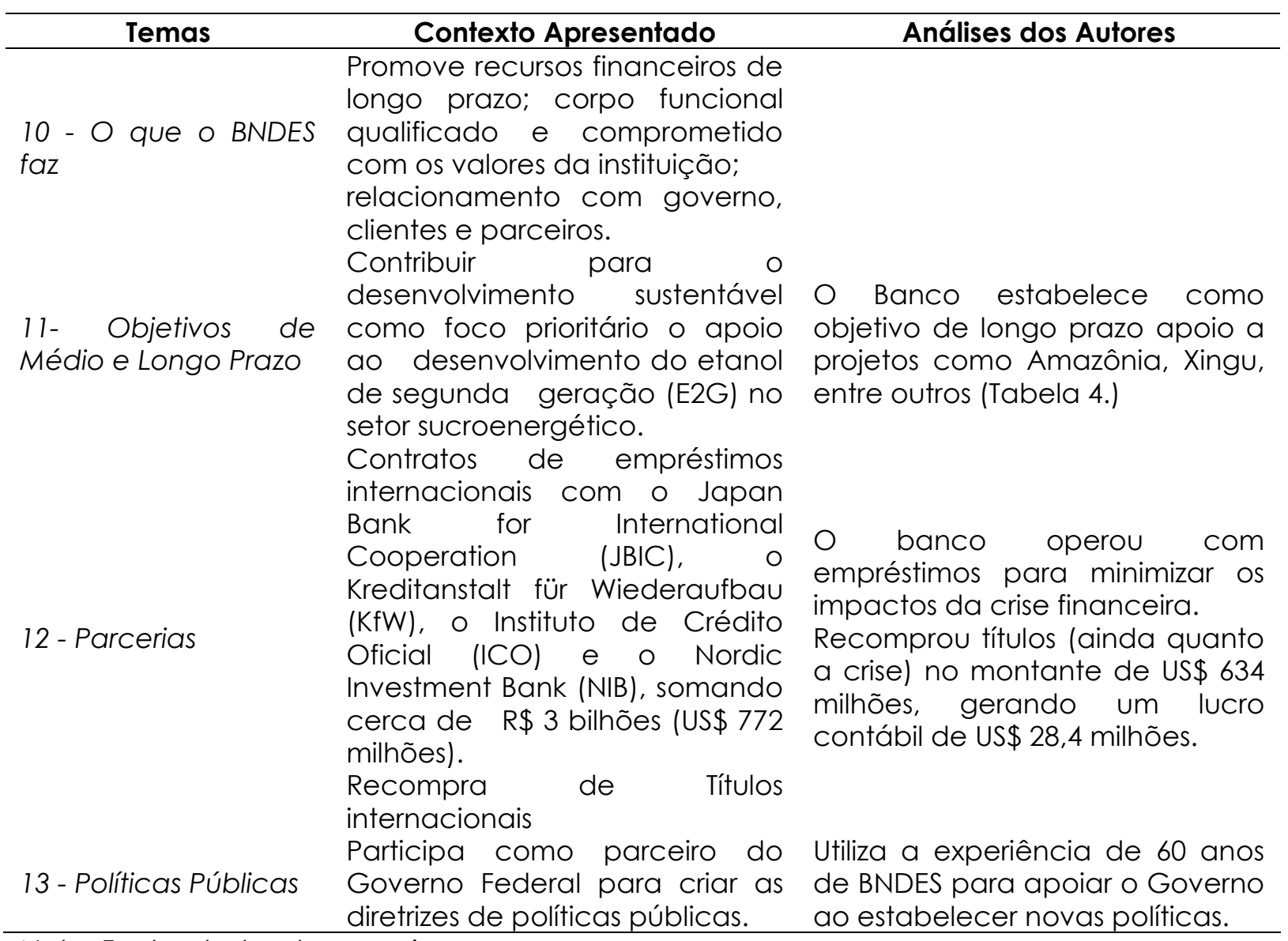

Nota. Fonte: dados da pesquisa.

Na Tabela 4 são apresentados os temas relacionados a divulgação de Desenvolvimento Sustentável do BNDES, segregados na unidade de contexto (ii) projetos.

\section{Tabela 4}

Relações encontradas ao tema projetos

\begin{tabular}{|c|c|c|}
\hline Temas & Contexto Apresentado & Análises dos Autores \\
\hline $\begin{array}{l}1 \text { - Apoio a } \\
\text { Exportação }\end{array}$ & 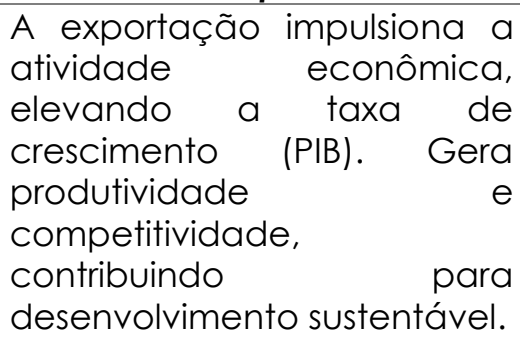 & $\begin{array}{l}\text { O Banco apresenta setores aos } \\
\text { quais destina exportação e os outros } \\
\text { atores que participam do processo } \\
\text { de financiamento, como exemplo } \\
\text { Banco do Brasil. Dados não estão } \\
\text { mensurados na mesma moeda para } \\
\text { todos os anos. }\end{array}$ \\
\hline $\begin{array}{l}2 \text { - Desenvolvimento } \\
\text { de Competências }\end{array}$ & Treinamento a funcionários. & $\begin{array}{l}\text { Apresenta } \quad \text { horas } \\
\text { desenvolvimento concedido de } \\
\text { funcionários para ações de inclusão } \\
\text { social. }\end{array}$ \\
\hline $\begin{array}{l}3 \text { - Dimensão } \\
\text { Regional e Setorial }\end{array}$ & $\begin{array}{l}\text { Apresenta } \\
\text { regionais. }\end{array}$ & $\begin{array}{l}\text { BNDES trabalha em todas as } \\
\text { regiões do País e apresenta } \\
\text { demonstrativos com a evolução do } \\
\text { investimento em cada região. }\end{array}$ \\
\hline
\end{tabular}




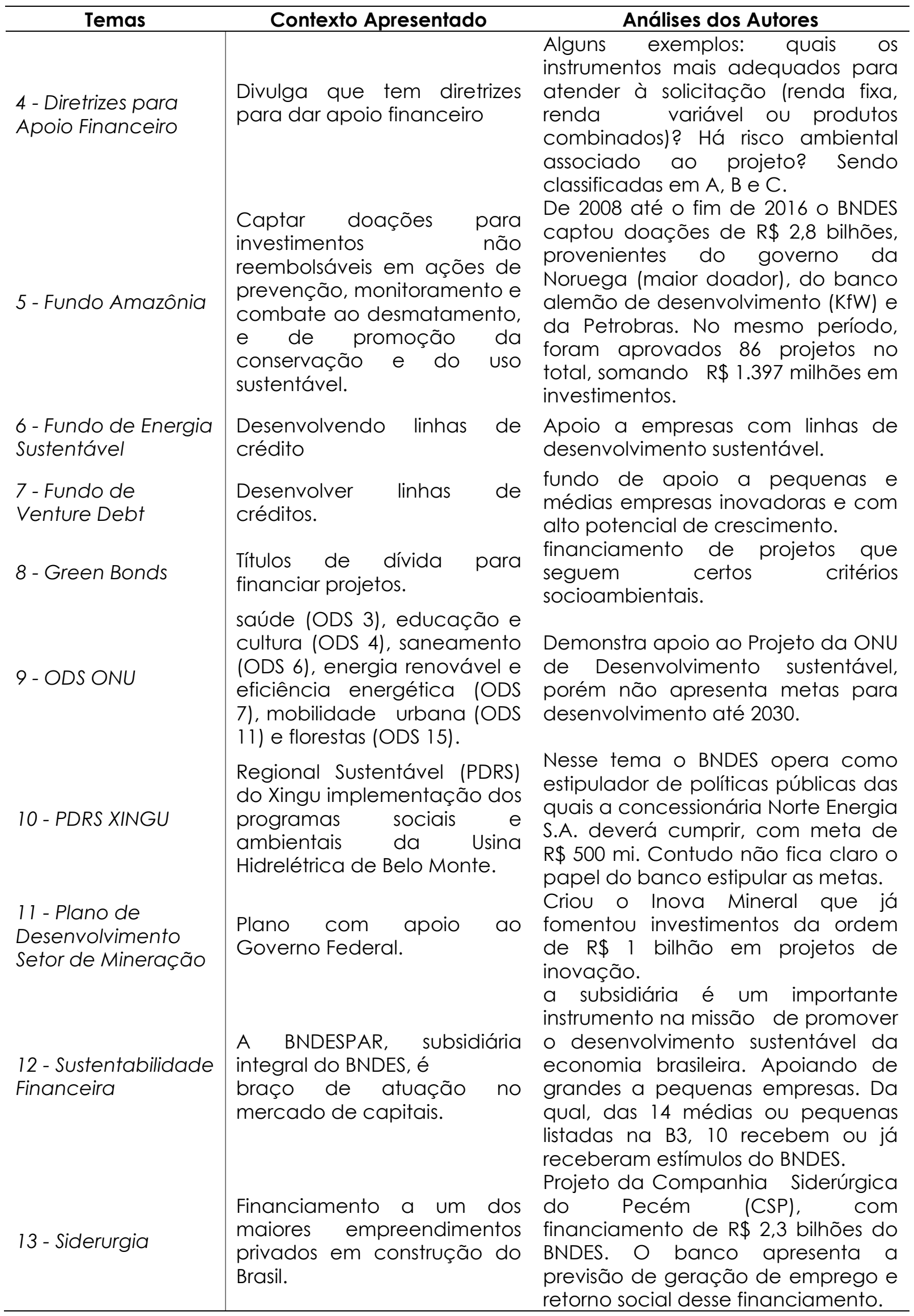

Nota. Fonte: dados da pesquisa. 
Diante das análises apresentadas na Tabela 3 e 4, observa-se que 0 BNDES tem direcionado seus projetos para o desenvolvimento sustentável do País. Para isso, estabeleceu ao longo dos anos analisados, apoio financeiro desde setores regionais, considerando expansão de Norte a Sul, à incentivo para exportação. Nesse último, exportação, vale destacar que entre 2013 e 2014, houve uma redução de concessão financeira para a exportação, contudo esta redução não pode ser comparada entre os anos de 2015 e 2016 , pois o BNDES divulgou os valores em moedas diferentes, sendo: 2013 UU\$ 7,1; 2014 UU \$ 4,4; 2015 R 6,8 e 2016 R \$ 14,9. Não possibilitando a comparabilidade dos dados, neste ponto do relato.

A Figura 3, apresenta uma visão geral dos temas encontrados nas duas temáticas.

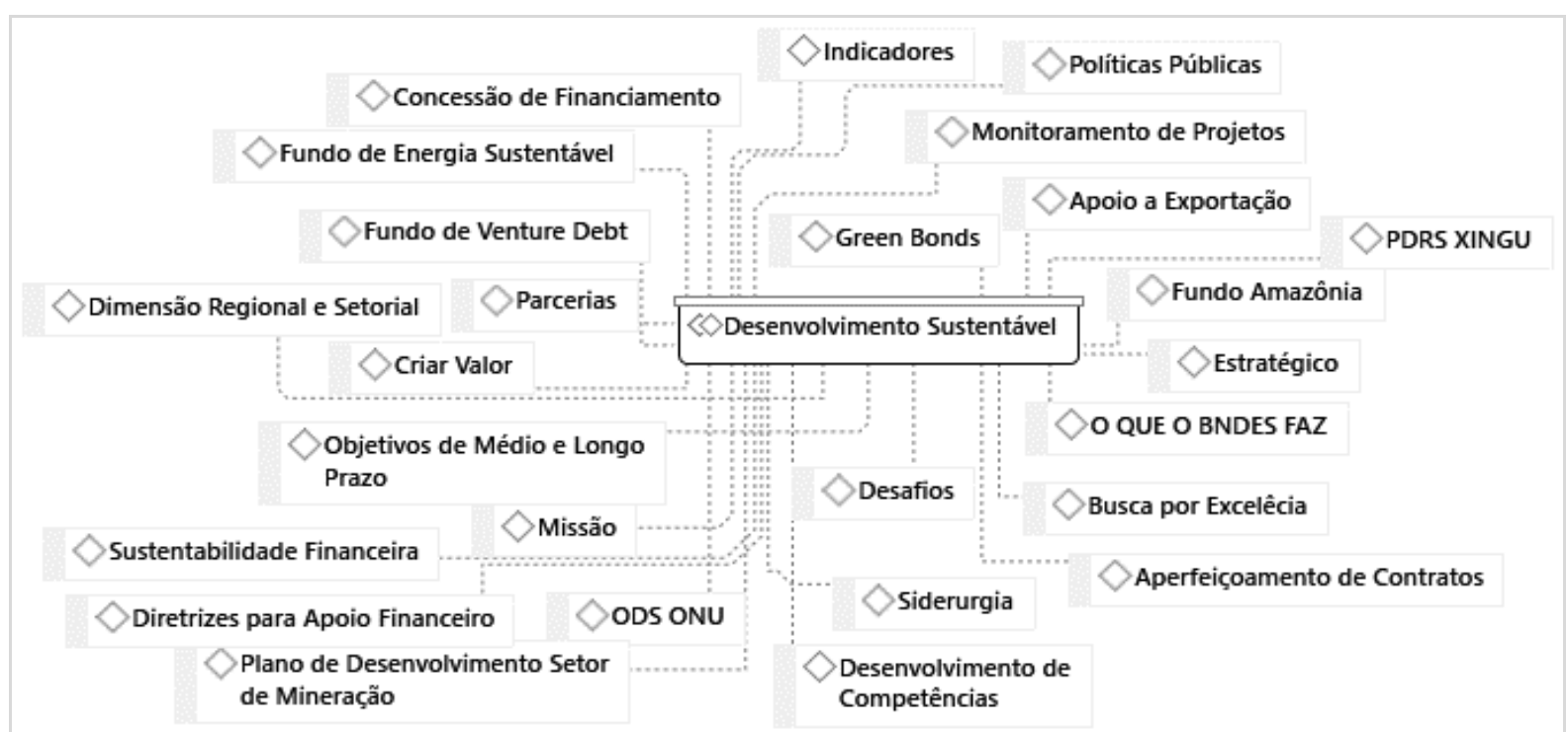

Figura 3. Temas de Desenvolvimento Sustentável

Fonte: Gerado no Atlas*ti com dados da pesquisa.

O resultado corrobora com a literatura apresentada (Cho et al., 2012; Hopwood, 2009; Elkington, 2012), identificando que o BNDES está reportando temas relacionados ao meio ambiente e âmbito social, atendendo a perspectiva que o século XXI (Elkington, 2012). A próxima seção discute esses resultados.

\section{DISCUSSÃO DOS RESULTADOS}

Na teoria da legitimidade temos o argumento de que se a organização não justificar a sua continuidade perante a sociedade poderá ter o seu contrato social revogado (Deegan, 2002; Richardson, 1987; Suchman, 1995), o BNDES tem um contrato social político com a sociedade brasileira, isso representa dizer que a instituição tem um contrato de desenvolvimento com empresas, microempresários, com governantes regionais, com setores avançados em outros países que precisam ser desenvolvidos no Brasil (como a tecnologia). Tal contrato, é posto em prática de acordo com as estratégias governamentais, logo se o governo objetivar impulsionar a internacionalização fará aportes em empresas que farão tal ponte, como ocorreu na última década (2010). Fato é que, ao fazer tal ponte entre a esfera executiva e mercado privado, a 
instituição fica em evidência caso tais investimentos sejam mal aplicados, nesse ponto volta-se para a importância do contrato social e sua legitimidade.

Embora o BNDES divulgue projetos de desenvolvimento sustentável não é possível afirmar nessa pesquisa que todas suas práticas têm retorno para o desenvolvimento sustentável, ou seja, que as práticas de concessão de crédito de hoje, não comprometerá as gerações futuras. Para tal afirmativa, destaca-se as reflexões e críticas apontadas não tópico 4.1 (Hochstetler, 2014; Lazzarini et al., 2015; Pezzin, 2015), ao inferir quanto as fases políticas entre as décadas de 1960 e os anos 2000, assim como o processo de internacionalização de grupos econômicos. Há um paradoxo entre fazer o percurso do contrato de legitimação com a sociedade a longo prazo e adotar diretrizes políticas de curto prazo.

O BNDES tem medidas de legitimidade social ao divulgar projetos como da Usina de Xingu (item 10, Tabela 4), no qual estabelece políticas públicas para a comunidade em que foi construída a hidrelétrica e do qual nesse período houveram diversos protestos contra a implementação da Usina.i Na literatura (Cho et al., 2012; Deegan, 2002; Roberts, 1992) essa estratégia está frente à necessidade de evitar qualquer ameaça a legitimidade da organização e seu ambiente, provida da relação entre as mesmas. No entanto o que fica em cheque é estabelecer até que ponto as diretrizes do banco, ao conceder um financiamento, são postas em práticas pôr as empresas considerando que a sustentabilidade ainda é vista como um desvio de finalidade econômica das organizações e possível Cavalo de Tróia (Spence, 2007), uma vez que, no que tange a concessão de financiamentos não foram estabelecidos indicadores suficientes para analisar o retorno desses investimentos.

Percebe-se que âmbito econômico, social e ambiental está presente nas práticas de desenvolvimento sustentável divulgadas no BNDES, assim como ocorre com o Fundo de Desenvolvimento de Energia Sustentável (tema 6, Tabela 4). Contudo, como posto por Elkington (2012) o BNDES também tem uma falha quanto indicadores que mensurem a sustentabilidade, no qual apresenta os valores financiados, mas nem sempre o possivel retorno deste investimento para a sociedade, o que corrobora com a perspectiva de Cho et al. (2012) ao discorrer que o fornecimento de informações em relatórios voltados a sustentabilidade é limitado.

Ante à falta de indicadores e pontos como a incomparabilidade de moeda no financiamento de exportações (apresentas no 4.2), depreende-se que o Relato Integrado pode levar a ideia de cavalo de tróia para o BNDES quanto a sua legitimidade (Spence, 2007; Bommel, 2014; Elkington, 2012). Isso porque a possibilidade de vincular uma visão holística da organização que são os preceitos do Relato Integrado e demonstrar se a mesma se mantém sustentável a longo prazo ou não, ainda é um desafio desse presente contemporâneo ao BNDES, ainda mais em meio a escândalos quanto ao financiamento de grandes empresas envolvidas na Operação Lava Jatoiii.

Conforme Abramovay (2010) e Preston e Post (1981), as políticas públicas devem ser analisadas e monitoradas para extrair propostas relevantes entre corporações e desenvolvimento sustentável. Uma possibilidade para o BNDES estabelecer esses parâmetros de forma sistêmica é apresentar os Objetivos de Desenvolvimento Sustentável (ODS) de forma mais completa e sistêmica. No 
O Percurso do Contrato de Legitimação para o Desenvolvimento Sustentável: Análise dos Temas Atrelados no Relato Integrado do BNDES

item 9 exposto na Tabela 3, foi demonstrado quais ODS são atendidos, no entanto não foram estabelecidas as metas de desenvolvimento deste para a Agenda de 2030iv ou segredadas as regiões a serem fortalecidas conforme preconizam as metas do ODS estabelecidas pela ONU. Diante disso, percebe-se um paradoxo entre ter pressões de diversos stakeholders (por exemplo, a Rede Brasil sobre Instituições Financeiras Multilaterais) e os mesmos terem meios para monitorar as políticas sociais estabelecidas pelo o BNDES, que é uma instituição com capacidade de influência nos caminhos que o país irá percorrer.

No tópico 4.1, foi apresentado as fases políticas que o BNDES percorreu, com críticas entre os anos de 2010 a 2013 quanto a internacionalização concedendo crédito a grupos empresariais, levando a suposta oligopolização das operações. Na sequência o tópico 4.2 detalha os temas estratégicos que o BNDES está financiando atualmente, entretanto, analisando apenas o Relato Integrado entre os anos 2013 a 2016, não foi possível inferir quanto a atual fase do BNDES, uma vez que não estava discriminado no relato para quais empresas (principais) os empréstimos foram concedidos. Portanto, ressalta-se que de acordo com a justificativa apresentada para este estudo, que os 23 elementos divulgados e aqui segmentados como temas (Figura 3), apresentam uma janela do que seriam os atributos setoriais e regionais da mudança no desenvolvimento sustentável do Brasil e efetiva transformação (desenvolvimento) da sociedade brasileira para os próximos anos, visto que os seus financiamentos visam o desenvolvimento a longo prazo.

Os relatórios voluntários que versam responsabilidade corporativa podem ser vistos como contratos para a prática de legitimidade (Deegan, 2002; Gray, 2010; Hopwood, 2009), mas o fornecimento dessas informações tende ser limitado (Cho, Freedman, \& Patten, 2012), bem como a asseguração das tem limitações. A adoção ao Relato Integrado como demonstrativo de visão a longo prazo pode ser um mecanismo para relatar o papel do BNDES como banco de desenvolvimento em uma perspectiva sustentável, pois, como proposto por Thomson (2015), o Relato é baseado na suposição de usuários empoderados para monitorar, recompensar, disciplinar e punir organizações com práticas não aceitáveis. Assim, é uma alternativa para o percurso do contrato de legitimação do BNDES com o desenvolvimento sustentável evoluir concomitante a evolução da sua divulgação do Relato Integrado. O BNDES é uma corporação com capacidade de influenciar os caminhos que o país irá percorrer, logo, a adoção ao Relato Integrado como demonstrativo de visão a longo prazo poderá legitimar o papel do BNDES como banco de desenvolvimento em uma perspectiva sustentável.

\section{CONSIDERAÇÕES FINAIS}

Os pressupostos teoria da legitimidade e a literatura de sustentabilidade possibilitaram atender ao objetivo desta pesquisa de analisar quais os temas relacionados ao desenvolvimento sustentável que o BNDES tem trabalhado. Foram identificados 23 temas, em dois contextos (i) institucional e de (ii) projetos. Os resultados são sustentados com a literatura ao revelar que o BNDES atende sua visão de desenvolvimento sustentável, ante uma resposta a pressões de grupos com diferentes olhares e poderes na instituição que são de forma explícita no Relato Integrado do banco o Governo Federal e a Sociedade, que 
notam a ampliação dos riscos empresariais e voltam-se para que as entidades revejam a base na qual realizam seus negócios.

Conclui-se que propostas econômicas, sociais e ambientais estão presentes nas práticas de desenvolvimento sustentável do BNDES, assim como, foi divulgado o apoio a alguns fundos de desenvolvimentos sustentável. Entretanto, O BNDES tem uma falha quanto a indicadores que mensurem a sustentabilidade pois consegue apresentar os valores financiados, mas nem sempre o possível retorno deste investimento para a sociedade. Dessa forma, é possível sugerir que o BNDES está seguindo um caminho de desenvolvimento sustentável, mas para confirmar esse aspecto seria necessário avançar para novas pesquisas analisando de forma cada tema apresentado para afirmar que o percurso do contrato de legitimação do desenvolvimento sustentável está sendo efetivo.

As empresas, com algumas exceções, entendem que a sustentabilidade pode acarretar um desvio de finalidade em suas funções que é a maximização do lucro, não deveria ser considerado ao tratar do BNDES, pois sua própria missão é fornecer o desenvolvimento sustentável. No entanto pode-se levantar a questão de até onde o interesse político influência no real desenvolvimento sustentável do banco.

Contribui-se para a literatura de RSC atrelando teoria da legitimidade como um processo de retorno as pressões políticas e sociais para com o BNDES, estabelecendo que o Relato Integrado pode estar relacionado a uma forma de contrato de legitimação com diversos stakeholders, atrelando a missão do banco de desenvolvimento a longo prazo ainda que a sua gestão esteja relaciona aos mandatos públicos de curto prazo. Considerando que o enfoque da legitimação está voltado para o tipo de informação e a mensagem que se espera transmitir com ela, em termos práticos contribui, para evidenciar que o BNDES incorporou a mensagem do desenvolvimento sustentável no Relato Integrado, apesar de não ter conseguido medir ou mensurar.

Além disso, ao constar que os ODS da Agenda 2030 não estão definidos por metas, sugere-se apresentação sistêmica dos objetivos estabelecidos e as metas almejadas para 2030. Considera-se que a sistematização possibilitaria visão geral das diretrizes adotadas regionalmente para o percurso do desenvolvimento sustentável do Brasil, uma vez que o Relato Integrado é uma ferramenta para comunicar a todos stakeholders de como a organização gera valor.

Embora defendível teoricamente e metodologicamente, uma limitação nesse estudo é que se delimitou para encontrar quais os temas trabalhados no desenvolvimento sustentável, não tendo como objetivo investigar cada temática encontrada. Nesse sentido, para estudos posteriores, a sugestão está em levantar os dados de investimentos para o desenvolvimento sustentável de cada tema, assim como sugerir indicadores para mensuração dos mesmos.

Uma segunda limitação da pesquisa, é entender o BNDES e instituições de desenvolvimento no Brasil como uma pesquisa incipiente na literatura, considerando os poucos artigos indexados em bases de dados da área de ciências sociais aplicadas. Para tanto, estabelece que os achados desta pesquisa podem abrir lacunas para próximas pesquisas relacionando os 23 temas apresentados. 
O Percurso do Contrato de Legitimação para o Desenvolvimento Sustentável: Análise dos Temas Atrelados no Relato Integrado do BNDES

\section{REFERÊNCIAS}

Abramovay, R. (2010) Desenvolvimento sustentável: qual a estratégia para o Brasil? Novos Estudos Cebrap (Impresso), v. 87, p. 97-113. Disponível em: https://www.scielo.br/pdf/nec/n87/a06n87.pdf

Abramovay, R. (2012). Muito Além da Economia Verde. Editora Ab ed. São Paulo.

Adams, C. A. (2015). The International Integrated Reporting Council: A call to action. Critical Perspectives on Accounting, v. 27, p. 23-28. https://doi.org/10.1016/j.cpa.2014.07.001.

Aronovich, S.; Fernandes, A. G. (2006). A Atuação do Governo no Mercado de Crédito: Experiências de IFDs em Países Desenvolvidos. Revista do BNDES, v. 13, n. 25, p. 3-34, $2006 . \quad$ Disponível em: https://web.bndes.gov.br/bib/jspui/handle/1408/13513

Bachiller, J. V. (2016). Das Privatizações à Nova Estratégia de Desenvolvimento A Trajetória do BNDES entre 1990 e 2010. Desenvolvimento em Questão, v. 14, n. 36, p. 5-30. https://doi.org/10.21527/2237-6453.2016.36.5-30

BNDES. (2017). Livro Verde: nossa história como ela é / BNDES. 2017

Bommel, K. VAN. Towards a legitimate compromise? An exploration of Integrated Reporting in the Netherlands. Accounting, Auditing \& Accountability Journal, v. 27, n. 7, p. 1157-1189, 2014.

Burke, J. J.; Clark, C. E. (2016). The business case for integrated reporting: Insights from leading practitioners, regulators, and academics. Business Horizons, v. 59, p. 273-283. https://doi.org/10.1016/j.bushor.2016.01.001

Chen, J. C.; Roberts, R. W. (2010). Toward a More Coherent Understanding of the Organization-Society Relationship. Journal of Business Ethics, v. 97, p. 651-665, 2010. https://doi.org/10.1007/s10551-010-0531-0

Cho, C. H.; Freedman, M.; Patten, D. M. (2012) Corporate disclosure of environmental capital expenditures A test of alternative theories. Accounting, Auditing \& Accountability Journal, v. 25, n. 3, p. 486-507. https://doi.org/10.1108/09513571211209617

Colombo, A. L.; Andrade, N. T. H. Desigualdades regionais e bancos públicos: o papel do bndes na federação brasileira. Perspectivas, v. 47, p. 67-87, 2016.

Cosenza, J. P.; Mamede, E.; Laurencel, L. DA C. (2010). Análise dos fundamentos teóricos associados à pesquisa contábil na área ambiental. Enfoque, v. 29, n. 1, p. 18-38. https://doi.org/10.4025/enfoque.v29i1.10359 
Deegan, C. (2002) The Legitimising Effect of Social and Environmental Disclosures - A Theoretical Foundation. Accounting, Auditing \& Accountability Journal, v. 15, n. 3, p. 282-31 1. https://doi.org/10.1108/09513570210435852

Doctor, M. (2005). Assessing the Changing Roles of the Brazilian Development Bank. Bulletin of Latin American Research, v. 34, n. 2, p. 197-213. https://doi.org/10.1111/blar.12210

Elkington, J. Cannibals with forks: the triple bottom line of 21 st century business. Oxford: Capstone Publishing Limited, 1999.

Fank, O. L.; Beuren, I. M. (2010). Evidenciação das estratégias de legitimidade da tipologia de suchman (1995) nos relatórios da administração da petrobras. RCO - Revista de Contabilidade e Organizações, v. 4, n. 10, p. 25-47. https://doi.org/10.11606/rco.v4i10.34775

Ferraz, J. C.; Coutinho, L. (2017). Investment policies, development finance and economic transformation: Lessons from BNDES. Structural Change and Economic Dynamics. https://doi.org/10.1016/j.strueco.2017.11.008.

Flower, J. (2015). The International Integrated Reporting Council: A story of failure. Critical Perspectives on Accounting, v. 27, p. 1-17. https://doi.org/10.1016/j.cpa.2014.07.002

Garzon, L. F. N. (2015). Política socioambiental e de entorno do BNDES: dos ajustes espaciais aos corretivos territoriais - os casos das UHEs de Santo Antônio e Jirau ( RO ) e da UHE de Belo Monte ( PA ). Revista Política e Planejamento Regional, v. 2, n. 2.

Giambiagi, F.; Pinheiro, F.; Giambiagi, F. (2011). A capacidade de desembolso do BNDES durante a década de 2010 A capacidade de desembolso do BNDES durante a década de 2010. Revista BNDES, v. 36.

Gray, R. (2010). Is accounting for sustainability actually accounting for sustainability and how would we know? An exploration of narratives of organisations and the planet. Accounting, Organizations and Society, v. 35 , n. 1, p. 47-62, 2010. https://doi.org/10.1016/j.aos.2009.04.006

Hanley, A.; Pires, J. M.; Marcondes, R. L.; Faria, R. N.; Sakurai, S. N. (2016). Critiquing the Bank: 60 Years of BNDES in the Academy. Journal of Latin American Studies, $v$. 48, n. 4, p. 823-850. https://doi.org/10.1017/S0022216X16001814

Hochstetler, K. (2014). The Brazilian National Development Bank goes International: Innovations and Limitations of BNDES' Internationalization Special Section Article. Global Policy, v. 5, n. 3, p. 360-365. https://doi.org/10.1111/1758-5899.12131

Hopwood, A. G. (2009). Accounting and the environment. Accounting, Organizations and Society, v. 34, p. 433-439. 
O Percurso do Contrato de Legitimação para o Desenvolvimento Sustentável: Análise dos Temas Atrelados no Relato Integrado do BNDES

https://doi.org/10.1016/j.aos.2009.03.002

Kraychete, E. S. (2016). O Banco Nacional De Desenvolvimento Econômico E Social (Bndes) E A Expansão De Empresas Brasileiras De Construção Civil Para A América Do Sul. CRH, v. 29, n. 03, p. 125-134. https://doi.org/10.1590/S010349792016000400009.

Lai, A.; Melloni, G.; Stacchezzini, R. (2014). Corporate Sustainable Development: is Integrated Reporting a Legitimation Strategy? Business Strategy and the Environment, v. 25, p. 165-177. https://doi.org/10.1002/bse.1863

Latres, H. M. M.; Lemos, C.; Falcon, M.; Magalhães, W. (2014). Arranjos produtivos locais e a experiência do BNDES. Liinc em Revista, v. 10, n. 2, p. 652-664. Disponível em: http://revista.ibict.br/linc/article/view/3596/3075

Lazzarini, S. G.; Musacchio, A.; Bandeira-de-Mello, R.; Marcon, R. (2015). What Do State-Owned Development Banks Do? Evidence from BNDES, 2002 - 09. World Development, v. 66, p. 237-253. https://doi.org/10.1016/j.worlddev.2014.08.016

Perego, P.; Kennedy, S.; Whiteman, G. (2016). A lot of icing but little cake? Taking integrated reporting forward. Journal of Cleaner Production, v. 136, n. July 2014, p. 53-64. https://doi.org/10.1016/j.jclepro.2016.01.106

Pezzin, D. C. (2015). Financiamentos do BNDES para concessões em transportes no Brasil : uma análise a partir da ótica do desenvolvimento regional. Revista Política e Planejamento Regional, v. 2, n. 1, p. 173-198.

Preston, L. E.; Post, J. E. (1981). Private Management and Public Policy. California Management Review, v. 23, n. 3, p. 56-62.

Quaglio, G. D. M.; Paiva, C. C. (2017). A questão regional e o BNDES: uma análise da conformidade entre a atuação do Banco e a Política Nacional de Desenvolvimento Regional (PNDR). Economia e Sociedade, v. 26, n. 2, p. 337-368. https://dx.doi.org/10.1590/1982-3533.2017v26n2art3.

Rezende, F. (2015). Working Paper N. 825 Why Does Brazil 's Banking Sector Need Public Banks? What Should BNDES Do? by Hobart and William Smith Colleges Electronic copy available at: http://ssrn.com/abstract=2544722 Preferred URL: why-does-brazils-banking-sector-need-. Levy Economics Institute, n. 825.

Richardson, A. J. (1987). Accounting as a legitimating institution. Accounting Organizations and Society, v. 12, n. 4, p. 341-355. https://doi.org/10.1016/0361-3682(87)90023-7

Roberts, R. W. (1992). Determinants Of Corporate Social Responsibility Disclosure: An Application Of Stakeholder Theory. , v. 17, n. 6. https://doi.org/10.1016/0361-3682(92)90015-K

Schapiro, M. G. (2017). Legalidade ou discricionariedade na governança de 
bancos públicos: uma análise aplicada ao caso do BNDES. Revista de Administração Pública, v. 51, n. 1, p. 105-128. https://doi.org/10.1590/00347612155828

Schlickmann, P. (2016). A Distribuição Geográfica Dos Aportes Do Bndes Para A Indústria Do Plástico, Da Borracha E Da Química No Brasil. Bol. Goia. Geogr, v. 36, n. 3, p. 463-481. https://doi.org/10.5216/bgg.v36i3.44553

Silva, L.; Pereira, M. (2017). Os financiamentos do BNDES à logística do setor sucroenergético ( 2002-2015 ): concentração e reforço do uso corporativo do território no Brasil 1. As ações do Estado Brasileiro e atividades sucroenergéticas. Revista de Geografia e Ordenamento do Território, , n. 12, p. 335-356. http://dx.doi.org/10.17127/got/2017.12.015

Simonassi, Andrei Gomes, Arraes, Ronaldo de Albuquerque e, \& Silva, José Henrique Felix. (2017). Política de Crédito do BNDES e Sustentabilidade de Crescimento do Setor Primário. Revista de Economia e Sociologia Rural, 55(1), 31-46. https://doi.org/10.1590/1234-56781806-94790550102

Sobreira, R.; Martins, N. M. (2011). Os Acordos de Basileia e bancos de desenvolvimento no Brasil : uma avaliação do BNDES e do BNB. Revista de Administração Pública, v. 45, n. 2, p. 349-376. https://doi.org/10.1590/S003476122011000200004.

Souza, M. J. P. DE; Ferreira, A. L.; Hanley, A.; (2015). A quantitative analysis of the academic economic literature regarding the Brazilian Development Bank ( BNDES l. Economi, v. 16, n. 2, p. 157-175. http://dx.doi.org/10.1016/j.econ.2015.03.006

Spence, C. (2007). Social and environmental reporting and hegemonic discourse. Journal Accounting, Auditing \& Accountability, v. 20, n. 6, p. 855882. https://doi.org/10.1108/09513570710830272.

Suchman, M. C. (1995). Managing Legitimacy: Strategic And Institutional And Strategic Managing Legitimacy: Approaches. Academy of Management Review, v. 20, n. 3, p. 571-610. https://doi.org/10.2307/258788

Thomson, I. (2015). But does sustainability need capitalism or an integrated report ' a commentary on 'The International Integrated Reporting Council: A story of failure ' by Flower , J . Critical Perspectives on Accounting, v. 27, p. 18-22, 2015. 10.1016/j.cpa.2014.07.003

Torres, E. T. F.; Nogueira, F. (2012). BNDES e o financiamento do desenvolvimento. Economia e Sociedade, v. 21, p. 975-1009. https://doi.org/10.1590/S010406182012000400011 
O Percurso do Contrato de Legitimação para o Desenvolvimento Sustentável: Análise dos Temas Atrelados no Relato Integrado do BNDES

' https://portal.tcu.gov.br/imprensa/noticias/tcu-adota-relato-integrado-para-a-prestacao-de-contas-daadministracao-publica-federal.htm

ii https://economia.estadao.com.br/noticias/geral,ibama-libera-licenca-ambiental-de-operacao-para-belomonte, 10000002816

iiihttps://www.correiobraziliense.com.br/app/noticia/economia/2019/01/08/internas economia,729538/obras -com-recursos-do-bndes-sao-investigadas.shtml

iv https://nacoesunidas.org/pos2015/agenda2030/

\section{CONTRIBUIÇÕES DOS AUTORES}

\begin{tabular}{|c|c|c|c|}
\hline Contribuição & $\begin{array}{l}\text { Kelli Juliane } \\
\text { Favato }\end{array}$ & $\begin{array}{l}\text { Marguit } \\
\text { Neumann }\end{array}$ & $\begin{array}{l}\text { Simone Leticia } \\
\text { Raimundini } \\
\text { Sanches }\end{array}$ \\
\hline $\begin{array}{l}\text { 1. Idealização e concepção do assunto e } \\
\text { tema da pesquisa }\end{array}$ & $\checkmark$ & $\checkmark$ & \\
\hline 2. Definição do problema de pesquisa & $\checkmark$ & $\checkmark$ & $\checkmark$ \\
\hline $\begin{array}{l}\text { 3. Desenvolvimento da Plataforma } \\
\text { Teórica }\end{array}$ & $\checkmark$ & & $\checkmark$ \\
\hline $\begin{array}{l}\text { 4. Delineamento da abordagem } \\
\text { metodológica da pesquisa }\end{array}$ & $\checkmark$ & $\checkmark$ & \\
\hline 5. Coleta de dados & $\checkmark$ & & \\
\hline $\begin{array}{l}\text { 6. Análises e interpretações dos dados } \\
\text { coletados }\end{array}$ & $\checkmark$ & & \\
\hline 7. Conclusões da pesquisa & $\checkmark$ & $\checkmark$ & \\
\hline 8. Revisão crítica do manuscrito & $\checkmark$ & $\checkmark$ & $\checkmark$ \\
\hline $\begin{array}{l}\text { 9. Redação final do manuscrito, } \\
\text { conforme as normas estabelecidas pela } \\
\text { Revista. }\end{array}$ & $\checkmark$ & $\checkmark$ & \\
\hline 10. Orientação & & $\checkmark$ & \\
\hline
\end{tabular}

